\title{
ACALYPHA WILKESIANA regulates fluid volume but affects selected tissues in salt loaded rabbits
}

\author{
Kingsley Omage ${ }^{1 *}$ (D) and Marshall A. Azeke ${ }^{2}$
}

\begin{abstract}
Background: In folk medicine, Acalypha wilkesiana is often used in the treatment of various ailments, although this has not been fully rationalized scientifically. This study was conducted to evaluate the effects of Acalypha wilkesiana leaf extracts on fluid volume and selected tissues in salt loaded rabbits.

Methods: Thirty rabbits were randomized into five groups consisting of six animals each. Group 1 animals were fed with salt loaded diet continuously. Group 2 animals were fed with salt loaded diet followed by aqueous extract while animals in group 3 were fed with salt loaded diet followed by ethanol extract. Animals in group 4 were fed with salt loaded diet and distilled water while group 5 animals were fed with normal diet only.

Results: Salt loading resulted in a significantly $(P<0.05)$ higher ALT, AST and lower bicarbonate. Administration of Acalypha wilkesiana leaf extracts resulted in a significantly $(P<0.05)$ lower serum sodium, chloride, bicarbonate and AST activities. Histology revealed that salt loading had no effect on the heart, but caused mild vacuolation in the liver, and marked lymphocytosis of the kidney. Administration of the aqueous extract caused blood vessel congestion in the heart, shrinking of portal vein in the liver and congestion of blood vessels in the kidney. Also, administration of the ethanol extract caused distortion in blood vessels in the heart, congestion of the portal vein in the liver and marked lymphocytosis in the kidneys.
\end{abstract}

Conclusion: It is advisable to be moderate in the use of Acalypha wilkesiana in folk medicine.

Keywords: Acalypha wilkesiana, Salt loaded diet, Ethanol and aqueous extract, Fluid volume, Histology

\section{Background}

Increase in blood pressure in rats and rabbits has been induced by $8 \% \mathrm{NaCl}(w / w)$ loaded diet [1-3]. There is a possible relationship between excess salt intake and increased blood pressure [4-6]. Epidemiological studies have shown that excess dietary salt intake is related to the incidence of high blood pressure in some communities [7, 8]. A high-salt diet (salt loading), an independent determinant of renal injury [9-11], enhances ventricular and renal fibrosis in normotensive and spontaneously hypertensive rats (SHR) [12, 13]. The increased blood pressure causes damage to the kidney, heart, blood vessels, etc. In folk medicine, the deleterious effects of

\footnotetext{
* Correspondence: omagekingsley@yahoo.com

${ }^{1}$ Department of Biochemistry, School of Basic Medical Sciencces, College of Health Sciences, Igbinedion University, Okada, Benin City, Edo State, Nigeria Full list of author information is available at the end of the article
}

excess salt are often managed with the use of medicinal herbs.

Acalypha wilkesiana (Irish petticoat) is a medicinal herb that has found wide use in folk medicine. Igwe et al., (2016) [14] reported that the ethanolic leaf extract of Acalypha wilkesiana contain pharmacologically useful active phytochemicals. GCMS (Gas Chromatography-Mass Spectrometry) analysis of the phytochemical constituents of the ethanolic leaf extract of Acalypha wilkesiana revealed the presence of 12 compounds among which the most abundant were 2-Ethyl-1-hexene, n-Haxadecanoic acid or palmitic acid, and Butane 1,4-diol. These compounds are known to possess various medicinal potentials [14]. High performance liquid chromatography (HPLC) analysis indicated that Acalypha wilkesiana leaf is rich in flavonoids, carotenoids, and phytosterols, but very low in simple terpenes [15]. Among the six phytosterols detected in Acalypha 
wilkesiana leaves by Onyeike et al., (2010) [15], the levels of stigmasterol and $\beta$-sitosterol were the highest while Myrcene, $\beta$-amyrin, lupeol and thujene were the highest among the twelve simple terpenes detected. Their results showed that the leaves are potential sources of allelochemicals and nutraceuticals [15]. Acalypha wilkesiana is often used solely or as a major constituent of many herbal preparations [16]. However, its use has not been fully rationalized scientifically. Thus, this study was conducted to evaluate the effects of Acalypha wilkesiana leaf extracts on fluid volume and selected tissues in salt loaded experimental rabbits.

\section{Materials and methods}

\section{Plant materials and extract preparation}

Acalypha wilkesiana leaves used for this study were freshly obtained from Santua horticultural garden within Benin City and authenticated at the Department of Plant Biology and Biotechnology, University of Benin, Benin City. The leaves were properly washed under a running tap water, air-dried, ground into fine powder and weighed. One hundred gram each of the fine powder was soaked in $400 \mathrm{ml}$ each of absolute ethanol (ethanol extract) and distilled water (aqueous extract) for $72 \mathrm{~h}$. The mixtures were occasionally stirred using a magnetic stirrer. After three days of soaking, the mixtures were filtered using a sintered funnel. The filtrates (extracts) were concentrated using a rotary evaporator and the concentrates weighed. About $5 \mathrm{~g}$ each of the dry mass of the concentrated extracts were suspended in distilled water for administration to the experimental rabbits.

\section{Preparation of salt-loaded diet $(8 \% \mathrm{NaCl})$}

This was prepared by mixing $8 \mathrm{~g}$ of analytical $\mathrm{NaCl}$ (from BDH Chemicals England) with $92 \mathrm{~g}$ of the feed.

\section{Experimental animals}

The experimental animals used for this study were thirty adult rabbits of the New Zealand strain, weighing between $1.0-1.6 \mathrm{~kg}$. The rabbits were obtained from local breeders and kept in the animal house of the Department of Biochemistry, University of Benin. They were maintained on a 12-h light and dark cycle in clean disinfected cages and allowed free access to feed (standard pelletized growers feed from UAC- Vital Feed, Jos, Plateau State) and water. After three weeks of acclimatizing to the new environment, they were randomized into five groups (groups 1 to 5) of six animals each. The experimental procedures performed on the animals were as approved by the Animal Ethics Committee of the Faculty of Life Sciences, University of Benin, Nigeria. The use of rabbits for the study was also according to the Ethical Guidelines Involving Whole Animal Testing of the Animal Ethics Committee, Faculty of Life Sciences, University of Benin.

\section{Experimental design}

The rabbits in the groups (1 to 5 ) were treated as follows;

Group 1 rabbits: were fed with salt-loaded diet continuously.

Group 2 rabbits: were fed with salt-loaded diet and aqueous extract (Aq. Ext) of Acalypha wilkesiana leaves Group 3 rabbits: were fed with salt-loaded diet and ethanol extract (Et. Ext) of Acalypha wilkesiana leaves Group 4 rabbits: were fed with salt-loaded diet and distilled water (DW)

Group 5 rabbits: were fed with normal diet (Control).

\section{Details}

The rabbits in groups 1, 2, 3 and 4 were fed with the salt-loaded diet for a period of seventy (70) days. After day 70, group 1 animals were continued on the salt loaded diet till the 77th day. Groups 2 and 3 animals were discontinued on the salt loaded diet after day 70 and administered with aqueous and ethanol extracts of Acalypha wilkesiana leaves respectively till the 77 th day (i.e. the extracts were administered for a period of seven days). Also, after day 70, group 4 animals were discontinued on the salt-loaded diet and administered with distilled water till the 77th day, while group 5 animals were fed with normal diet only.

\section{Route and dose of extracts administration}

The extracts (aqueous or ethanol) were administered to the rabbits orally at a dose of $300 \mathrm{mg} / \mathrm{kg}$ body weight for a period of 7 days.

\section{Sample collection \\ Blood}

After 70 days of salt loaded diets and prior to administration of the extracts, blood samples were collected from the rabbits using sterilized hypodermic needles. At day 78 after treatment with the extracts for a period of 7 days, blood samples were also collected from the animals. The blood samples were centrifuged at $3500 \mathrm{rpm}$ for $10 \mathrm{~min}$ to obtain a clear serum which was used for biochemical analysis.

\section{Organs}

At day 78, the animals were sacrificed and the organs (Heart, Liver and Kidney) harvested. They were rinsed in normal saline and the tissues processed for histology.

\section{Histology}

Haematoxylin and Eosin (H \& E) staining technique was used to study the general structure of the tissues. 


\section{Assay methods}

Flame photometer was used to determine the concentration of Potassium and sodium by the method of Tietz, 1987 [17]. Chloride concentration was determined by the method of Skeggs and Hoschstrasser 1964 [18]. The concentration of Bicarbonate was determined by the method of Van slyke, 1925 [19]. The method of Connerty and Biggs, 1966 [20] was used for the determination of calcium concentration. Urea was determined by the method of Weatherbum 1967 [21] (Urease Berthelot method). Creatinine concentration was by the method of Bartels and Bohmer, 1972 [22]. Alanine aminotransferase (ALT) and Aspartate aminotransferase (AST) were determined by the method of Reitman and Frankel.

\section{Data analysis}

Data analysis was by ANOVA and Turkey-Kramer test (GraphPad Instat Version 3). Statistical Significance was set at $P<0.05$ and data presented as Mean \pm S.E.M $(n=$ $6)$.

\section{Results}

The effects of oral administration of extracts (aqueous or ethanol) of A. wilkesiana leaves on serum sodium, potassium, chloride, calcium, bicarbonate, urea, creatinine, ALT, AST and some organs (liver, heart and kidney) of salt loaded experimental rabbits, are as shown below.

Serum sodium concentrations were significantly $(P<0.05)$ higher in all the salt loaded groups as compared with the control, after 70 days of salt loading (Table 1). At day 78; group 1 (given continuous salt loading) still showed a significantly $(\mathrm{P}<0.05)$ higher sodium concentrations compared with group 5, while group 4 showed a non-significantly $(P>0.05)$ higher concentration after cessation of salt loading. But administration of the aqueous extract (groups 2$)$ resulted in significantly $(P>0.05)$ lower sodium concentrations, while administration of the ethanol extract resulted in non-significantly lower sodium concentrations, as compared with group (4).

Serum potassium concentrations were non-significantly $(P>0.05)$ higher in the salt loaded groups as compared with the non-loaded group (control), after 70 days of salt loading (Table 1). But at day 78, all the salt loaded groups showed non-significantly $(P>0.05)$ lower concentrations compared with the control (group 5). Administration of the extracts had no significant $(p>0.05)$ effect in the treated groups as compared with the non-treated group.

Serum chloride concentration was shown to be non-significantly $(\mathrm{P}>0.05)$ higher in all the salt loaded groups as compared with the non-loaded group (control), after 70 days of salt loading (Table 1). Administration of the extracts, however, resulted in significantly $(P<0.05)$ lower chloride concentrations in group 2 (given aqueous extract) and non-significantly $(p>0.05)$ lower concentrations in group 3 (given ethanol extract). But, in comparison, the various groups showed no significant difference $(P>0.05)$ in the serum chloride concentrations.

Table 1 also show that after 70 days of salt loading, groups $1,3 \& 4$ (given salt load) showed non-significantly $(P>0.05)$ lower serum calcium concentrations, while group 2 (also given salt load) showed significantly $(p<0.05)$ lower concentrations, compared with the control (group 5). At day 78 , these differences were leveled out $(1 \& 4$ as compared with 5). However, administration of the extracts after one week resulted in non-significantly $(P>0.05)$ lower calcium concentrations in group 2 (treated with the aqueous extract) and significantly $(p<0.05)$ lower concentrations in group 3 (treated with the ethanol extract) as compared with the untreated group.

In Tables 2, 70 days of salt loading resulted in a significantly $(P<0.05)$ lower bicarbonate concentrations in all the salt loaded groups, compared with the control. But after one week of administration, the aqueous extract resulted in a significantly $(\mathrm{P}<0.05)$ lower bicarbonate concentrations (group 2 compared with group 4). Also, at

Table 1 The effects of oral administration of extracts (aqueous or ethanol) of A. wilkesiana leaves on serum sodium, potassium, chloride and calcium concentrations of salt-loaded rabbits

\begin{tabular}{|c|c|c|c|c|c|c|}
\hline & & GROUP & & & & \\
\hline SERUM & DAY & 1 (Cont. Salt) & 2 (Salt+Aq. Ext) & 3 (Salt +Et. Ext) & 4 (Salt+DW) & 5 (Control) \\
\hline \multirow[t]{2}{*}{ SODIUM (mEq/l) } & 71 & $123.67 \pm 4.67^{\mathrm{ax}}$ & $120.67 \pm 2.85^{\mathrm{ax}}$ & $124.67 \pm 2.03^{\mathrm{ax}}$ & $124.33 \pm 4.70^{\mathbf{a x}}$ & $104.67 \pm 0.88^{\mathbf{b x}}$ \\
\hline & 78 & $122.67 \pm 0.33^{d x}$ & $103.67 \pm 5.84^{\mathrm{ey}}$ & $115.00 \pm 4.00^{\mathrm{cx}}$ & $117.00 \pm 1.00^{\mathbf{c x}}$ & $106.33 \pm 1.45^{c x}$ \\
\hline \multirow{2}{*}{$\begin{array}{l}\text { POTASSIUM } \\
(\mathrm{mEq} / \mathrm{l})\end{array}$} & 71 & $13.40 \pm 1.56^{\mathbf{a x}}$ & $12.87 \pm 3.5^{\mathbf{a x}}$ & $9.33 \pm 2.50^{\text {ax }}$ & $7.17 \pm 0.37^{\mathrm{ax}}$ & $8.63 \pm 0.67^{\mathrm{ax}}$ \\
\hline & 78 & $\begin{array}{l}5.30 \pm 0.66^{\text {by }} 60 \% \\
\text { decrease }\end{array}$ & $\begin{array}{l}4.50 \pm 0.15^{\text {by } 65 \%} \\
\text { decrease }\end{array}$ & $\begin{array}{l}5.37 \pm 0.73^{\text {by } 42 \%} \\
\text { decrease }\end{array}$ & $\begin{array}{l}4.33 \pm 0.37^{\text {bx }} \mathbf{4 0} \% \\
\text { decrease }\end{array}$ & $\begin{array}{l}6.50 \pm 0.81^{\text {bx } 25 \%} \\
\text { decrease }\end{array}$ \\
\hline \multirow{2}{*}{$\begin{array}{l}\text { CHLORIDE (mEq/ } \\
\text { l) }\end{array}$} & 71 & $102.12 \pm 1.69^{a}$ & $112.43 \pm 7.25^{\mathbf{a x}}$ & $102.38 \pm 3.38^{\mathbf{a x}}$ & $108.73 \pm 1.59^{\text {ax }}$ & $96.30 \pm 9.51^{\text {ax }}$ \\
\hline & 78 & $74.68 \pm 2.78^{\mathbf{b}}$ & $69.06 \pm 9.06^{\text {by }}$ & $82.45 \pm 2.53^{\mathbf{b x}}$ & $85.87 \pm 2.65^{\mathbf{b x}}$ & $85.51 \pm 1.63^{\mathbf{b x}}$ \\
\hline \multirow[t]{2}{*}{ CALCIUM (mg/dl) } & 71 & $9.60 \pm 0.37^{a x}$ & $9.24 \pm 0.07^{\mathbf{b x}}$ & $9.81 \pm 0.09^{\mathrm{ax}}$ & $9.78 \pm 0.18^{\mathrm{ax}}$ & $10.36 \pm 0.23^{a x}$ \\
\hline & 78 & $10.45 \pm 0.04^{d x}$ & $9.83 \pm 0.16^{\mathbf{d x}}$ & $9.20 \pm 0.64^{\mathbf{c x}}$ & $10.17 \pm 0.36^{\mathbf{d x}}$ & $10.84 \pm 0.11^{d x}$ \\
\hline
\end{tabular}

Data are presented as Means \pm S.E.M $(n=6)$. Means with different symbol ${ }^{\mathbf{x}, \mathbf{y}}$ along columns and ${ }^{\mathbf{a}, \mathbf{b}, \mathbf{c} \& \mathbf{d}}$ along rows are significantly different $(p<0.05)$ 
Table 2 The effects of oral administration of extracts (aqueous or ethanol) of A. wilkesiana leaves on serum bicarbonate, urea and creatinine concentrations of salt-loaded rabbits

\begin{tabular}{|c|c|c|c|c|c|c|}
\hline & & GROUP & & & & \\
\hline SERUM & DAY & 1 (Cont. Salt) & 2 (Salt+ Aq. Ext) & 3 (Salt +Et. Ext) & 4 (Salt+DW) & 5 (Control) \\
\hline \multirow{2}{*}{$\begin{array}{l}\text { BICARBONATE } \\
(\mathrm{mmol} / \mathrm{l})\end{array}$} & 71 & $28.16 \pm 5.81^{\mathrm{ax}}$ & $30.79 \pm 2.09^{\mathbf{a x}}$ & $37.37 \pm 1.05^{\mathbf{a x}}$ & $34.74 \pm 2.73^{\mathbf{a x}}$ & $59.74 \pm 3.10^{\mathbf{b x}}$ \\
\hline & 78 & $\begin{array}{l}42.10 \pm 1.60^{\text {dy } 33 \%} \\
\text { increase }\end{array}$ & $\begin{array}{l}11.31 \pm 0.53^{\text {cy } 63 \%} \\
\text { decrease }\end{array}$ & $\begin{array}{l}14.21 \pm 2.41^{\text {cy }} 62 \% \\
\text { decrease }\end{array}$ & $\begin{array}{l}15.79 \pm 1.64^{\text {cy } 55 \%} \\
\text { decrease }\end{array}$ & $\begin{array}{l}29.74 \pm 3.73^{\text {ey } 50 \%} \\
\text { decrease }\end{array}$ \\
\hline \multirow[t]{2}{*}{ UREA (mg/dl) } & 71 & $37.08 \pm 2.59^{\mathrm{ax}}$ & $35.52 \pm 1.74^{\mathrm{ax}}$ & $32.38 \pm 1.60^{\mathbf{a x}}$ & $29.84 \pm 1.38^{\mathbf{a x}}$ & $34.86 \pm 3.43^{\mathrm{ax}}$ \\
\hline & 78 & $33.38 \pm 4.34^{\mathbf{b x}}$ & $35.32 \pm 0.28^{\mathbf{b x}}$ & $46.42 \pm 0.61^{c y}$ & $33.97 \pm 1.69^{\mathbf{b x}}$ & $37.65 \pm 2.86^{\mathbf{b x}}$ \\
\hline \multirow[t]{2}{*}{ CREATININE (mg/dl) } & 71 & $0.86 \pm 0.13^{\mathbf{a x}}$ & $0.88 \pm 0.04^{\mathrm{ax}}$ & $0.97 \pm 0.16^{\mathbf{a x}}$ & $1.17 \pm 0.06^{\mathrm{ax}}$ & $1.01 \pm 0.02^{\mathrm{ax}}$ \\
\hline & 78 & $0.81 \pm 0.06^{\mathbf{b x}}$ & $0.76 \pm 0.04^{\mathbf{b x}}$ & $0.83 \pm 0.06^{\mathbf{b x}}$ & $0.93 \pm 0.06^{\mathbf{b x}}$ & $0.85 \pm 0.09^{\mathbf{b x}}$ \\
\hline
\end{tabular}

Data are presented as Means \pm S.E.M $(n=6)$. Means with different symbol ${ }^{\mathbf{x}, \mathbf{y}}$ along columns and ${ }^{\mathbf{a}, \mathbf{b}, \mathbf{c} \boldsymbol{\&} \mathbf{d}}$ along rows are significantly different $(p<0.05)$

day 78, group 1 showed increase in bicarbonate concentrations while the other groups showed decreases, with their respective percentages as indicated.

The groups given salt load showed no significant $(P>0.05)$ difference in the concentrations of urea compared with the control (group 5), as shown in Table 2. This observation was the same at day 78, except for the group given ethanol extract (group 3 ) which showed a significantly $(P<0.05)$ higher urea concentrations compared with the non-administered group (4).

As compared to the control (group 5), there was no significant difference in creatinine concentrations in all the groups given salt load (Table 2). Administration of the extracts after one week also did not result in any difference between the administered and un-administered groups. Thus, salt loading and/or administration of aqueous or ethanol extracts of Acalypha wilkesiana leaves resulted in non-significant $(p>0.05)$ effect on the concentrations of serum creatinine of the experimental animals.

In Table 3, salt loading resulted in serum alanine aminotransferase (ALT) activities that were significantly $(P<0.05)$ higher in all the salt loaded groups, as compared with the control group (group 5). At day 78, group 1 (given continuous salt) showed a significantly $(p<0.05)$ higher values and groups $3 \& 4$ showed non-significantly $(P>0.05)$ higher values, while group 5 showed non-significantly $(P>0.05)$ lower ALT activities.
Salt loading resulted in serum Aspartate aminotransferase (AST) activities that were significantly $(P<0.05)$ higher in all the groups given salt load as compared with the control group (group 5). At day 78, AST activities in group 1 (given continuous salt load) remained high as compared with the control. However, groups 2,3 \& 4 showed non-significantly $(\mathrm{P}>0.05)$ lower AST activities. Administration of the extracts (aqueous or ethanol), resulted in significantly $(\mathrm{P}<0.05)$ lower AST activities in the treated groups (groups $2 \& 3$ ), as compared with that of the untreated group (group 4). The ethanol extract was, however, shown to be more effective (Table 3).

Histology (Figs. 1, 2 and 3) revealed that salt load had no effect on the heart, resulted in mild vacuolation in the liver, and marked lymphocytosis of the kidney. Administration of the aqueous extract resulted in blood vessel congestion in the heart, shrinking of portal vein in the liver, and congestion of blood vessels in the kidney. While administration of the ethanol extract resulted in distortion of blood vessels in the heart, congestion of the portal vein in the liver and marked lymphocytosis in the kidneys of the salt loaded test rabbits.

\section{Discussion}

Some of the important functions of electrolytes include regulation of the amount of fluid (water) in the body and maintenance of blood $\mathrm{pH}$ within normal range. Individuals with hepatitis $\mathrm{C}$ or cirrhosis tend to retain

Table 3 The effects of oral administration of extracts (aqueous or ethanol) of A. wilkesiana leaves on Serum ALT and AST activities of salt-loaded rabbits

\begin{tabular}{|c|c|c|c|c|c|c|}
\hline & & GROUP & & & & \\
\hline SERUM & DAY & 1 (Cont. Salt) & 2 (Salt+ Aq. Ext) & 3 (Salt +Et. Ext) & 4 (Salt+DW) & 5 (Control) \\
\hline \multirow[t]{2}{*}{ ALT (U/L) } & 71 & $55.35 \pm 3.27^{\mathbf{a x}}$ & $42.17 \pm 3.69^{a x}$ & $39.77 \pm 9.22^{\mathbf{a x}}$ & $42.73 \pm 6.40^{\text {ax }}$ & $27.43 \pm 1.04^{\mathbf{b x}}$ \\
\hline & 78 & $61.12 \pm 4.28^{\mathrm{cx}}$ & $36.15 \pm 3.34^{\mathrm{dx}}$ & $45.20 \pm 1.34^{\mathrm{dx}}$ & $49.30 \pm 6.55^{\mathbf{d x}}$ & $29.77 \pm 5.46^{\mathbf{e x}}$ \\
\hline \multirow[t]{2}{*}{ AST (U/L) } & 71 & $72.80 \pm 9.80^{\mathbf{a x}}$ & $59.80 \pm 3.38^{\mathbf{a x}}$ & $69.33 \pm 6.27^{\mathbf{a x}}$ & $44.20 \pm 3.32^{\mathbf{a x}}$ & $32.77 \pm 6.82^{\mathbf{b x}}$ \\
\hline & 78 & $68.30 \pm 10.50^{\mathbf{c x}}$ & $34.27 \pm 1.21^{\mathbf{d y}}$ & $33.51 \pm 4.24^{\mathbf{d y}}$ & $36.30 \pm 1.20^{\mathbf{d x}}$ & $36.05 \pm 2.38^{d x}$ \\
\hline
\end{tabular}

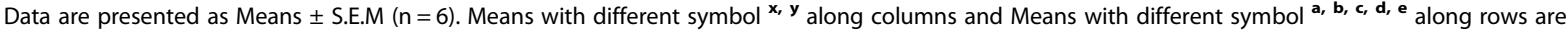
significantly different $(p<0.05)$ 


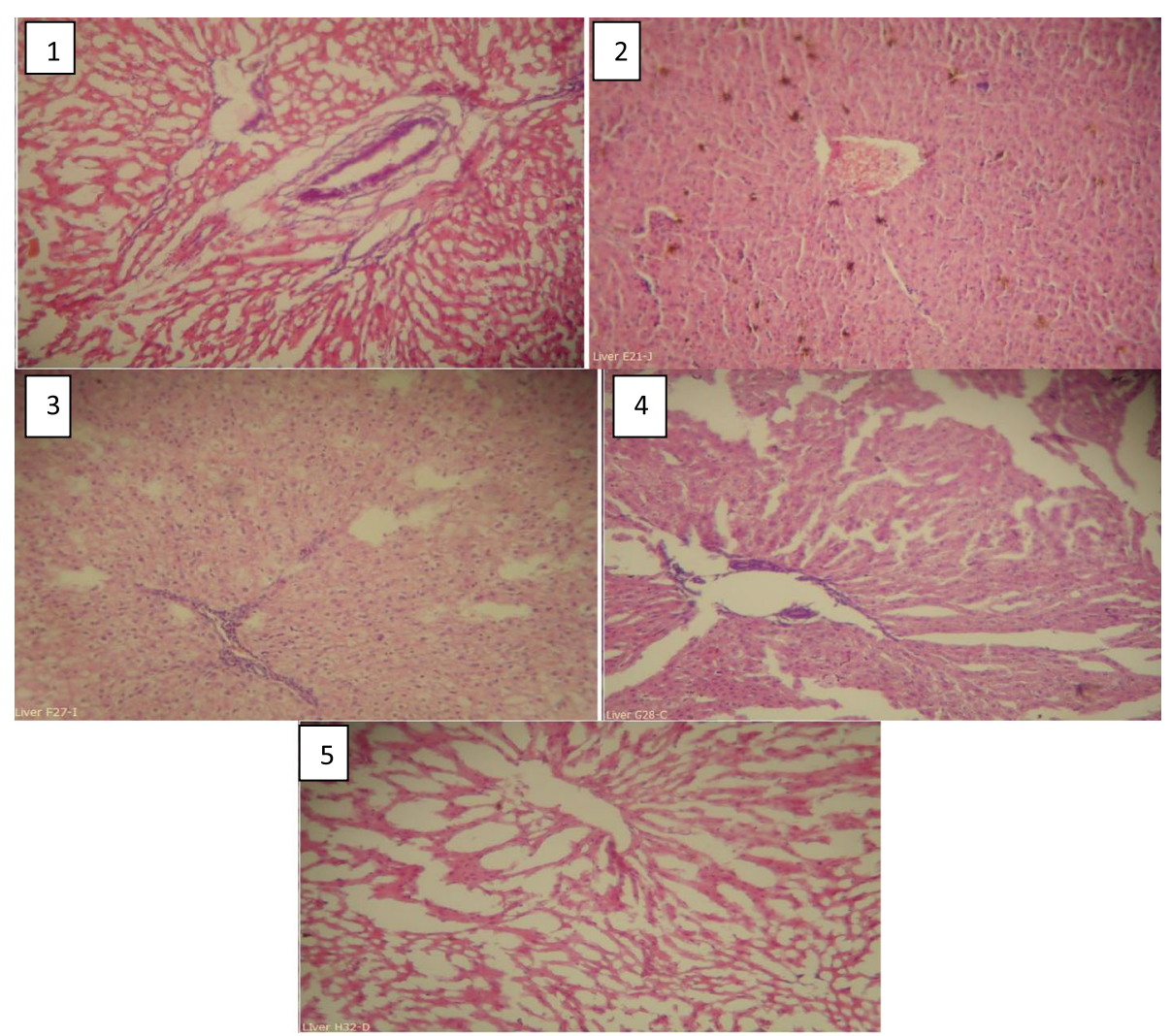

Fig. 1 Histological Sections of the Liver. Plate 1: Group (1): given continuous salt-load. There is periportal inflammation and mild vacuolation of the hepatocytes. Plate 2: Group (2): given salt-load and treated with aqueous extract. There is shrinking of the portal vein and granulation of hepatocytes Plate 3: Group (3): given salt-load and treated with ethanolic extract. There is infiltration and congestion of the porta vein as well as granulation of hepatocytes Plate 4: Group (4): given salt-load and distilled water. There is periportal inflammation and mild vacuolation of the hepatocytes. Plate 5: Control Group (5): given distilled water. The central portal vein appears normal

more water in the body than needed resulting in abnormal bicarbonate, chloride, potassium or sodium concentrations. Sodium is the principal cation in extracellular fluid which regulates plasma volume and acid-base balance. Increased dietary salt intake may promote organ damage through non-pressure related effects [23, 24]. Administration of the plant (A. wilkesiana leaf) extracts, which resulted in lower serum sodium concentrations of the treated groups, may be protective against these harmful effects or damage due to excess sodium in the system. Our previous studies with normal rabbits showed that the leaf extracts of the plant has a potential to maintain homeostasis by reducing the serum sodium concentrations of the experimental rabbits [25]. Maintenance of homeostasis (a possible effect of the plant) or regulation of plasma fluid volume is a preventive measure against organ damage that could possibly result from increased dietary salt intake $[25,26]$. This diuretic effect has been linked with the tannin content of the plant [27].

The natriuretic effect of potassium is important in reducing extracellular fluid volume and blood volume. The increase in serum potassium concentrations resulting from increased sodium load (salt load) may be due to the natriuretic effect of potassium which is aimed at countering the effect of excess sodium (homeostasis). The effects of the plant extracts may be more of moderating the concentrations of potassium as against that of sodium, so as to ensure normal sodium/potassium balance rather than reducing or increasing the concentrations of potassium $[25,26]$.

Chloride ion is an anion which is involved in the regulation of blood pressure, fluid and electrolyte balance. Severe dehydration, kidney failure or intravenous infusion of $\mathrm{NaCl}$ can cause increase chloride concentrations resulting in hyperchloremic metabolic acidosis. Increased salt load invariably resulted in increase serum chloride concentrations as observed. However, administration of the aqueous extracts resulted in significantly lower chloride concentrations while administration of the ethanol extract resulted in non-significantly lower chloride concentrations. The decrease in serum chloride concentrations in the treated group may be a protective implication of the plant against hyperchloremic acidosis. This is in agreement with our previous findings which 

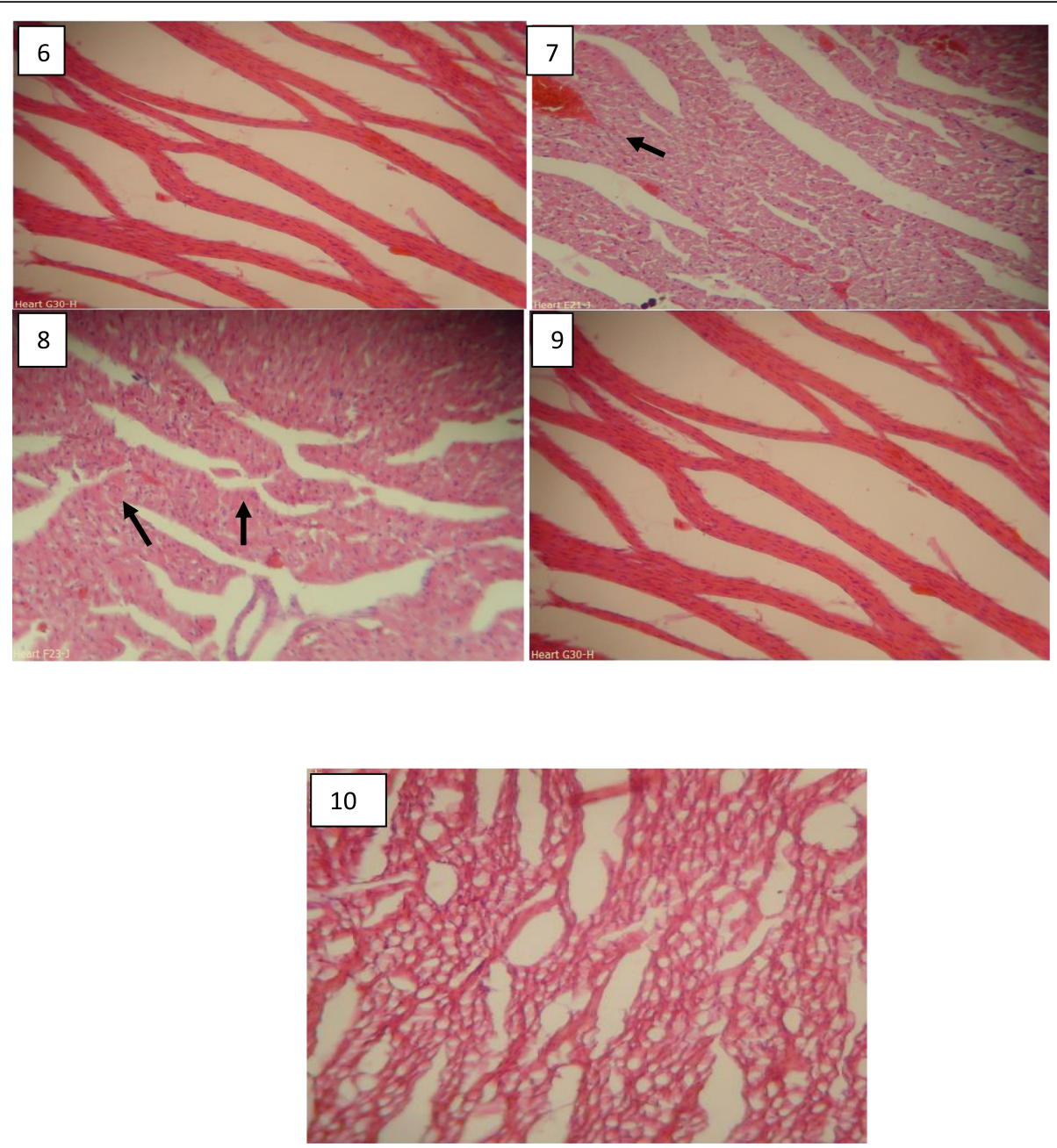

Fig. 2 Histological Sections of the Heart. Plate 6: Group (1): given continuous salt load. Showing normal cardiac muscle fibres. Plate 7: Group (2): given salt load and aqueous extract. The arrow indicates haemorrhage and congestion in blood vessels. Plate 8: Group (3): given salt load and ethanolic extract. The arrows indicate haemorrhage and distorted blood vessels. Plate 9: Group(4): given salt load and distilled water, shows normal cardiac muscle fibres. Plate 10: Control group (5): given distilled water Shows normal cardiac muscle fibres

showed that Acalypha wilkesiana leaf extracts may be beneficial in the prevention of metabolic acidosis due to excess sodium, accompanied with chloride [25].

Bicarbonate ion is a vital component of the $\mathrm{pH}$ buffering system of the body. Its value in the blood volume is one of several indicators of the state of acid-base physiology in the body. A significant decrease in serum bicarbonate, resulting from salt load, indicates that salt loading potentially disturbs the acid-base physiology of the system. The complementary effect of the aqueous extract also pose treat to the prolong use or excess dose of the plant as it has the potential of disturbing the acid-base homeostasis of the system. Calcium plays an important role in building stronger and healthy bones. Abnormalities in serum calcium concentration may have profound effects on neurological, gastrointestinal, and renal function. Increased sodium load may cause increase in calcium influx in the cardiac myocyte which resulted in reduced calcium concentrations in the salt loaded group as observed. Administration of the extracts also resulted in lower calcium concentrations as compared with the untreated group. Maintenance of normal serum calcium is due to tightly regulated ion transport by the kidney, intestinal tract and bone as mediated by calcaemic hormones especially parathyroid hormone and 1, 25-dihydroxyvitamin $\mathrm{D}_{3}$. Acalypha wilkesiana may have an effect on this maintenance process, as it has been shown to exert definite actions on different organs of the body [28].

Urea is known to play a major role in the urinary concentrating mechanism of mammals and also contributes to the osmolarity gradient in renal tissue in all states of water balance [29]. These functions may not be affected as salt loading did not significantly affect the urea concentrations of the experimental animals. However, administration of the ethanol 

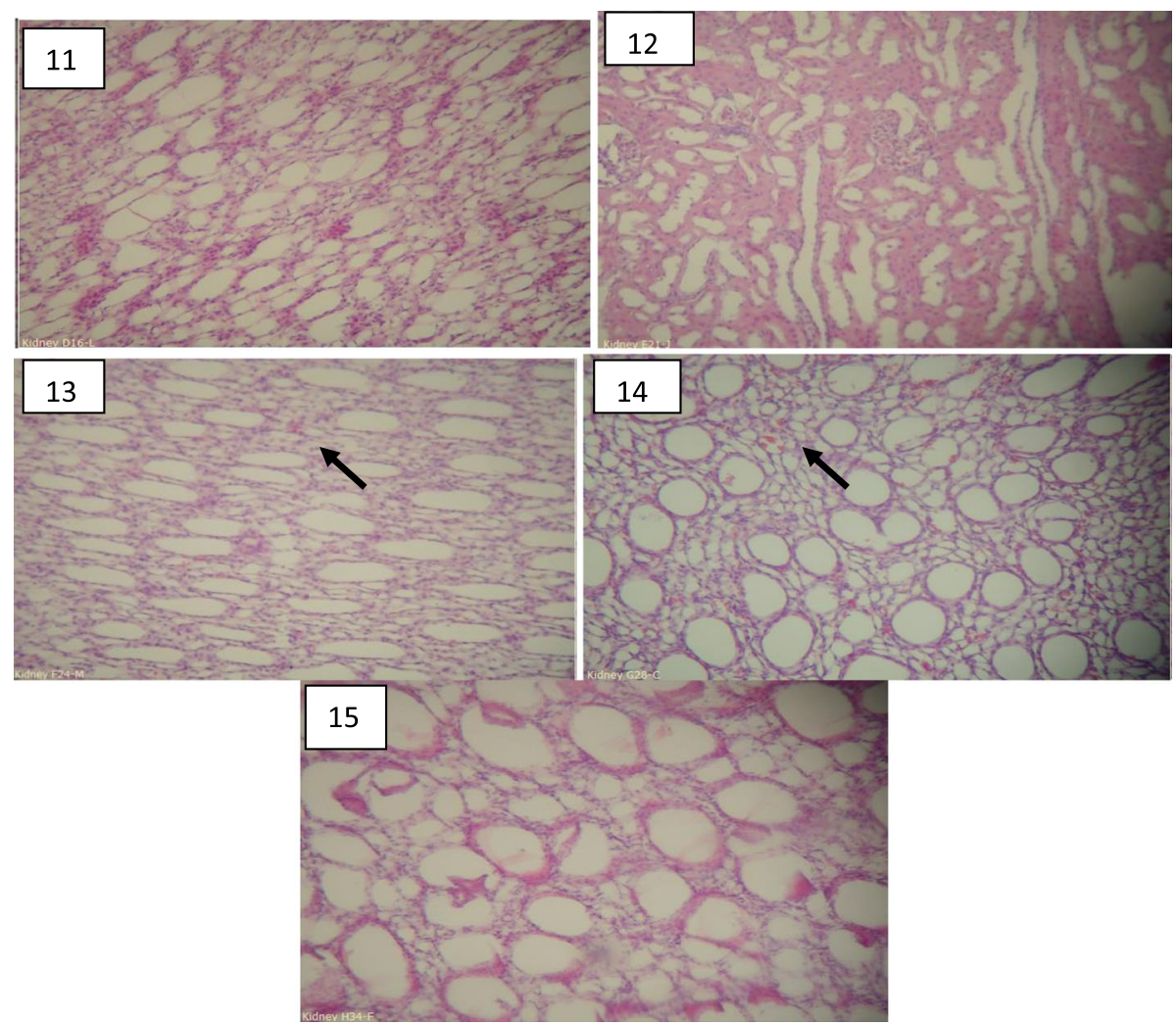

Fig. 3 Histological Sections of the Kidney. Plate 11: Group (1): given continuous salt load. The glomeruli appear to have marked lymphocytosis with hyperchromatic nucleus. Plate 12: Group (2): given salt load and aqueous extract. The glomeruli appear to have marked lymphocytosis with hyperchromatic nucleus and congested blood vesicles. Plate 13: Group (3): given salt load and ethanolic extract. The glomeruli appear to have marked lymphocytosis with hyperchromatic nucleus. There is also haemorrhage as indicated with an arrow. Plate 14: Group (4): given salt load and distilled water. The glomeruli appear to have mild lymphocytosis. There is also haemorrhage as indicated with an arrow. Plate 15: Control group (5): given distilled water. Shows normal glomerular of the kidney

extract which resulted in significantly higher urea concentrations may portend an increase in protein break down. However, this may not be directly due to tissue protein breakdown as our previous study on the nutritional composition of the plant showed increased amount of protein in the ethanol extract [16]. Creatinine which is a waste product of muscle cell metabolism is excreted by the kidneys into the urine. Its concentration is usually measured to assess the functional status of the kidney, with elevations indicating kidney problems. As compared to the control, there was no significant difference in creatinine concentrations in all the groups given salt load. Administration of the extracts also did not result in any difference between the treated and untreated groups. Although serum creatinine has poor predictive accuracy for renal injury, particularly in the early stages of acute kidney injury [30,31], salt loading and/or administration of aqueous or ethanol extracts of Acalypha wilkesiana leaves did not result in any significant effect on the concentrations of serum creatinine of the experimental animals.

Serum aminotransferase activities are sensitive indicators of parenchymal liver damage. Salt loading resulted in significantly higher serum ALT and AST activities in all the test groups. Administration of the extracts (aqueous or ethanol) resulted in significantly lower ALT and AST activities in the treated groups. This may portend a possible hepato-protective effect of the plant extract. The ethanol extract was however shown to be more effective. The sustained increase in AST activities of the group given continuous salt load as against the decrease in AST activities of the treated group is indicative of the possible adverse effect of the salt load on the functional status of the liver. This may be supported by the observed decrease in group D after cessation of salt load. The decrease in AST activities in the treated groups, resulting from the extracts, is also indicative of the possible protective effect of the plant against the adverse effects of salt load on the liver. The hepato-protective effect of the plant is also supported with results from our previous studies with normal experimental rabbits given aqueous or ethanol extracts of Acalypha wilkesiana leaves [32].

Increased salt-load in the diet will result in increased blood pressure [1, 2, 33]. This extra blood pressure puts strain on the arteries making the arterial walls stronger and thicker. Histology revealed that salt load had no effect on the heart, caused mild vacuolation in the liver, 
and marked lymphocytosis of the kidney. Administration of the aqueous extract caused blood vessel congestion in the heart, shrinking of portal vein in the liver, and congestion of blood vessels in the kidney. While administration of the ethanol extract caused distortion of blood vessels in the heart, congestion of the portal vein in the liver and marked lymphocytosis in the kidneys of the salt loaded test rabbits. Administration of the aqueous extract of Acalypha wilkesiana leaves also caused congestion in blood vessel and hemorrhage. It was, however, worse when treated with ethanol extract as the blood vessels were distorted and there was still hemorrhage. Increased salt-load on the liver, when left untreated resulted in periportal inflammation of the liver. Since the liver is a vascularized tissue, every cell death (necrosis) evokes an inflammatory reaction which is morphologically manifested by the appearance of inflammatory cells together with oedema and the presence of damaged blood vessels. There was also vacuolation of the untreated hepatocytes. Administration of either aqueous extract or ethanol extract, caused granulation of the hepatocytes which allows for the regeneration of the dead (necrosis) liver cells. However, administration of the aqueous extract resulted in the shrinking of the portal vein while administration of the ethanol extract resulted in the infiltration/congestion of the portal vein. When left untreated, and with continuous salt-load, it caused marked lymphocytosis, Hyperchromatic nucleus (a sign of malignancy) and haemorrhage. However, administration of the aqueous extract did not eliminate the haemorrhage, instead caused congestion of the blood vessels while administration of the ethanol extract showed no difference from when it was untreated. Despite the medicinal and/or therapeutic benefits of Acalypha wilkesiana in folk medicine, it is advisable to be moderate in its use in view of the possible harmful effects on the blood vessels.

\section{Conclusion}

Acalypha wilkesiana leave extracts (aqueous or ethanol) had a reducing effect on the serum sodium, and an increasing effect on potassium, which is beneficial in the regulation of fluid volume and maintenance of homeostasis. Histology revealed that salt load had no effect on the heart, caused mild vacuolation in the liver, and marked lymphocytosis of the kidney. Administration of the aqueous extract caused blood vessel congestion in the heart, shrinking of portal vein in the liver, and congestion of blood vessels in the kidney; while administration of the ethanol extract caused distorted blood vessels in the heart, congestion of the portal vein in the liver, and marked lymphocytosis in the kidneys of the salt loaded test animals. In view of the possible harmful effects on the blood vessels, it is advisable to be moderate in the use of Acalypha wilkesiana in folk medicine.

\section{Abbreviations}

ALT: Alanine Aminotransferase; Aq.: Aqueous; AST: Aspartate

Aminotransferase; Cont.: Continuous; Cr: Creatinine; DW: Distilled Water; Et.: Ethanol; Ext.: Extract; GCMS: Gas Chromatography-Mass Spectrometry; $\mathrm{HCO}_{3}^{-}$: Bicarbonate; HPLC: High performance liquid chromatography; OCC: o-cresolftalein complexone

\section{Acknowledgements}

The Authors are grateful to the authorities of Department of Biochemistry, Igbinedion University, Okada (Edo State, Nigeria) for providing the necessary laboratory facilities.

\section{Funding}

This work was self-funded by the authors.

\section{Availability of data and materials}

Data and materials on which conclusions of the manuscript rely are presented in the main paper.

\section{Authors' contributions}

$\mathrm{KO}$ contributions in the manuscript include the concepts, design, experimental studies, data acquisition and analysis, manuscript preparation and statistical analysis. MAA contributed in the concepts, design, experimental studies, data acquisition and analysis. Both authors read and approved the final manuscript.

\section{Authors' information}

$\mathrm{KO}, \mathrm{PhD}$, is a senior lecturer and research scientist in the department of biochemistry, Igbinedion University, Okada, Edo State, Nigeria. MAA, PhD, is a professor of Nutrition Biochemistry in the department of biochemistry, Ambrose Alli University, Ekpoma, Edo State, Nigeria.

\section{Ethics approval and consent to participate}

The experimental procedures performed on the animals were as approved by the Animal Ethics Committee of the Faculty of Life Sciences, University of Benin, Nigeria. The use of rabbits for the study was also according to the Ethical Guidelines Involving Whole Animal Testing of the Animal Ethics Committee, Faculty of Life Sciences, University of Benin.

\section{Consent for publication}

Not Applicable.

\section{Competing interests}

The authors wish to state that there are no competing interests associated with this publication and there has been no significant financial support for this work that could have influenced its outcome.

\section{Publisher's Note}

Springer Nature remains neutral with regard to jurisdictional claims in published maps and institutional affiliations.

\section{Author details}

${ }^{1}$ Department of Biochemistry, School of Basic Medical Sciencces, College of Health Sciences, Igbinedion University, Okada, Benin City, Edo State, Nigeria. ${ }^{2}$ Department of Biochemistry, Faculty of Life Sciences, Ambrose Alli University, Ekpoma, Edo State, Nigeria.

Received: 18 January 2018 Accepted: 21 January 2019

Published online: 20 February 2019

\section{References}

1. Osuntoki AA, Omonigbehin AE, Gbenebitse SO, Mojiminiyi UE. Prevention of salt induced hypertension in rats by oral administration of Lactobacillus acidophilus yoghurt. Nigerian Food Journal. 2007;25(1):184-9.

2. Antonio C, Isabel R, Rocío P, Miguel AV, Rosemary W, Andrés Q, Antonio O, Juan MM. Effects of Clofibrate on salt loading-induced hypertension in rats. J Biomed Biotechnol. 2011:1-8.

3. Adeleye OE, Sofola OA. Salt intake and mean arterial blood pressure in rabbits. Science World Journal. 2010;5(3):29-32.

4. Scott L, Hummel E, Mitchell S, Robert DB, Theodore JK, Samar SS. Lowsodium dietary approaches to stop hypertension diet reduces blood 
pressure, arterial stiffness, and oxidative stress in hypertensive heart failure with preserved ejection fraction. Hypertension 2012; 60 1200-1206.

5. Tanika NK, Casey MR, Dongfeng G, James EH, Treva KR, Jie C. Analysis of sex hormone genes reveals gender differences in the genetic etiology of blood pressure salt sensitivity: the GenSalt study. Am J Hypertens. 2013;26(2):191-200.

6. Héctor $P$, Atilio F, Yasmir $Q$, Freddy R, Gustavo P, Richard JJ. Immune reactivity to heat shock protein 70 expressed in the kidney is cause of saltsensitive hypertension. AJP - Renal Physiol. 2013;304(3):F289-99.

7. Wu L, Feng X, He A, Ding Y, Zhou X, Xu Z. Prenatal exposure to the great Chinese famine and mid-age hypertension. PLoS One. 2017:12(5):1-12.

8. Isezuo SA. Seasonal variation in hospitalisation for hypertension-related morbidities in Sokoto, north-western Nigeria International. Journal of Circumpolar Health. 2003;62(4):397-409.

9. Du Cailar G, Ribstein J, Mimran A. Dietary sodium and target organ damage in essential hypertension. Am J Hypertens. 2002;15:222-9.

10. Verhave JC, Hillege HL, Burgerhof JGM, Janssen WMT, Gansevoort RT, Navis GJ, de Zeeuw D, Jong PE. Sodium intake affects urinary albumin excretion especially in overweight subjects. J Intern Med. 2004;256:324-30.

11. Swift PA, Markandu ND, Sagnella GA, He FE, MacGregor GA. Modest salt reduction reduces blood pressure and urine protein excretion in black hypertensives: a randomized control trial. Hypertension. 2005;46:308-12.

12. Varagic J, Susic D, Matavelli LC, Frohlich ED. AT 1 receptor antagonism attenuates adverse cardiovascular and renal effects of salt excess in SHR without affecting arterial pressure. 59th Annual Fall Conference and Scientific Sessions of the Council for High Blood Pressure Research in Association with the Council on the Kidney in Cardiovascular Disease (Abstract). Hypertension. 2005; 46: 819.

13. Varagic J, Frohlich ED, Diez J, Susic D, Ahn J, Gonzalez A, Lopez B. Myocardial fibrosis, impaired coronary hemodynamics, and biventricular dysfunction in salt-loaded SHR. Am J Physiol Heart Circ Physiol. 2006;290: H1503-9.

14. Igwe KK, Madubuike AJ, Chika I, Amaku FJ. Studies on the medicinal plant Acalypha wilkesiana ethanol extract Phytocomponents by GCMS analysis. Int J Advanced Research in Science, Engineering and Technology. 2016;3(4): 1779-85.

15. Onyeike EN, Ikewuchi JC, Ikewuchi CC, Uwakwe AA. Quantitative high performance liquid chromatographic analysis of simple terpenes, carotenoids, Phytosterols and flavonoids in the leaves of Acalypha wilkesiana Muell Arg. Pacific Journal of Science and Technology. 2010;11(2):480-7.

16. Omage K, Azeke AM, Ihimire II, Idagan AM. Phytochemical. Proximate and elemental analysis of Acalypha wilkesiana leaves. Scientific Journal of Pure and Applied Sciences. 2013;2(9):323-31.

17. Sejin P, Hankil B, Taek DC. Electrochemical non-enzymatic glucose sensors. Anal Chim Acta. 2006;556(1):46-57.

18. Abd-EL-Roof YM. The role of ultrasonography and other aids in tile diagnosis of experimental surgical unilateral Hydronephrosis of dogs. Kafr El-Sheikh Vet Med J. 2006:4(1):745-61.

19. Robert EF, Susanna JD. Membrane transport and provision of substrates for carbonic anhydrase: in vertebrates. The Carbonic Anhydrases. 2000;90:263-80.

20. Okura N, Yamagishi N, Naito Y, Koiwa M. Dose response to vaginal administration of 1,25-dihydroxyvitamin $\mathrm{D}_{3}$ to cows. Vet J. 2007:174(1):203-5.

21. Meale SJ, Chaves AV, Baah J, McAllister TA. Methane production of different forages in In vitro ruminal fermentation. Asian-Australas J Anim Sci. 2012; 25(1):86-91.

22. Andersen S, Dehnfeld M, Laurberg P. Ethnicity is important for creatinine excretion among Inuit and Caucasians in Greenland. Scand J Clin Lab Invest. 2015;75(1):45-50

23. Frohlich ED, Varagic J. The role of sodium in hypertension is more complex than simply elevating arterial pressure. Nat. Clin. Pract. Cardiovasc. Med. 2004;: :24-30.

24. Meneton $P$, Jeunemaitre $X$, de Wardener HE, MacGregor GA. Links between dietary salt intake, renal salt handling, blood pressure, and cardiovascular diseases. Physiol Rev. 2005;85:679-715.

25. Omage K, Azeke AM, Orhue NEJ. Implications of oral administration of extracts of Acalypha wilkesiana leave on serum electrolytes, urea and creatinine in normal experimental rabbits. Biokemistri. 2015;27(2):56-62.

26. Ikewuchi JC, Ikewuchi CC. Effect of Acalypha wilkesiana muell Arg on the ATPase activities of salt-loaded rats. Pacific J Science and Technology. 2009; 10(2):823-8

27. Omage K, Azeke AM. Medicinal potential of Acalypha wilkesiana leaves. Advances in Research (AIR). 2014b;2(11):655-65.
28. Bailey CJ, Day C. Traditional plants medicines as treatments for diabetes Diabetes Care. 1989:12(8):553-64.

29. Brian KM. Water and Salt Exhange in Terestrial Vertebrates. In: The Physiological Ecology of Vertebrates: A view from Energetics. Uthaca, New York. USA: University Press. Sage House; 2002. p. 207-9.

30. Waikar SS, Betensky RA, Bonventre JV. Creatinine as the gold standard for kidney injury biomarker studies? Nephrol Dial Transplant. 2009;24:3263-5.

31. Hilde RHD, Michiel GB, Jan B. Biomarkers for the prediction of acute kidney injury: a narrative review on current status and future challenges. Clinical Kidney J. 2012;5:102-8.

32. Omage K, Azeke AM, Orhue NEJ, Iseghohi OS. Toxicological implications of the therapeutic use of Acalypha wilkesiana leaves in tradition medicine. Clinical Phytoscience. 2017;3(15):1-7.

33. Sofola OA, Knill A, Haisworth R, Drinkhill MJ. Change in endothelial function in mesenteric arteries of Spraque Dawley rats fed a high salt diet. J Physiol. 2002;543:255-60.

\section{Submit your manuscript to a SpringerOpen ${ }^{\circ}$ journal and benefit from:}

- Convenient online submission

- Rigorous peer review

- Open access: articles freely available online

- High visibility within the field

- Retaining the copyright to your article

Submit your next manuscript at $\boldsymbol{\nabla}$ springeropen.com 